\title{
Esfera da aplicação do Decreto 20.910 de 6 de janeiro de 1932
}

\author{
S. Soares de Faria
}

\section{(Parecer)}

1..$^{\circ}$ O Código Civil, em relação às obrigações passivas da Fazenda Pública, estabeleceu a prescrição de cinco anos $\left(178, \S 10, \mathrm{n}^{\circ} \mathrm{VI}\right)$. Mas êsse prazo podia tornar-se indefinito, sempre que o interessado tomasse a cautela de interrompê-lo, pois, por fôrça do disposto no Art. 173, lhe era sempre possivel não deixar esvair-se o seu direito, pondo em ação a fôrça interruptiva, geradora de uma nova prescrição.

Para obviar a êsse inconveniente, foi editado o Decreto 20.910 , de 6 de janeiro de 1932, com o intuito expresso de regular a prescrição quinquenal

e êsse diploma, no Art. $10^{\circ}$, estatuio que

as dívidas passivas da União, dos Estados e dos Municipios, bem assim todo e qualquer direito contra a Fazenda federal, estadual ou municipal, seja qual fôr a sua natureza, prescrevem em cinco anos, contados da data do ato ou fato do qual se originaram.

Não alterou o prazo prescricional, que continuou a ser o mesmo prazo

de cinco anos

tal qual prescrevia a lei civil. 


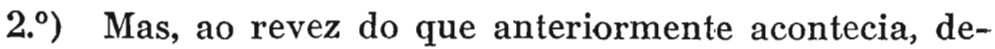
limitou a atividade interruptiva, com o prescrever, no art. $8 .^{\circ}$, que

a prescrição sómente poderá ser interrompida. uma vez

ie que, a nova prescrição, decorrente do exercício da faculdade legal, não seria mais de cinco anos, mas passaria a ser

da metade apenas daquele prazo

como ficou claramente previsto, no art. $90^{\circ}$ do mesmo decreto.

Não alterou, pois, o prazo prescricional, que continuou a ser de cinco anos. Cortou a possibilidade das renovações sucessivas, tolerou apenas uma, mas ainda assim, com o propósito evidente de liberar a Fazenda, restringio aquele prazo, da nova prescrição, para a metade, vale dizer para dois anos e meio, na hipótese de tratar-se de prescrição quinquenal.

$3^{\circ}$ ) De tal sorte, é óbvio que o diploma em apreço não abreviou o prazo prescricional

que êste continuou a ser de cinco anos, mas tão sómente estabeleceu um prazo menor para o caso especial de, na fluência do primeiro, ter obtido o titular do direito contra a Fazenda, pela prática de ato interruptivo, a sua inutilização e o exurgimento de uma nova prescrição

\section{I}

$4^{\circ}$ ) O problema, que o exame do texto do govêrno ditatorial provocou, é o de saber a que

prescrição interrompida

se refere o Art. $9 .^{\circ}$, problema, porém, que só surgio, pelo 
desconhecimento, de alguns intérpretes e aplicadores, de principios hoje elementares e comesinhos

a) do instituto da prescrição

b) do direito intertemporal.

Porque, si eles estivessem nítidos no pensamento de tais manejadores da lei, não poderia surdir a questão, porque, evidentemente, o verseto legal não poderia referir-se, que não às prescrições, que êle alcançou fluindo, pois outras não existiam, subvertidas que foram pela própria ação interruptiva.

5. ) Quando uma prescrição se interrompe, ela se esváe, do mesmo passo que uma outra a substitúe. E nisso se aparta ela da suspensão. Não existe mais a prescrição, que estava para consumar-se. $O$ ato interruptivo a destruio e, em seu logar, preenchendo o vácuo por ela deixado, colocou uma nova prescrição

que nada tem com a primeira, dela inteiramente desligada, autônoma e independente.

Vejamos a lição de um dos mais autorizados mestres na matéria:

Quando per una delle cause, a cui l'ordinamento giuridico attribuisce una simile potenza, la prescrizione rimane troncata e tutto il periodo di tempo già trascorso si há per inesistente si dice che la prescrizione è interrotta. Potrà o non ricominciare dopo la cessazione della causa interruttiva ma la prescrizione ricominciante stá da se, è independente da quella antica, che si considera come non avvenuta. (G. Pugliese La Prescizione nel Diritto Civile, I, n. 259, ed. 1911).

E o douto monografista, páginas adeante, salienta que é justamente êsse conceito especifico da interrupção 
o considerar-se como inexistente todo o periodo anterior, e o aparecimento de uma nova prescrição.

"A questo proposito è da aversi che il concetto speecifico della interruzione è questo: che dopo l'atto interruttivo, il quale fa considerare come inesistente tutto l'anteriore periodo di tempo, la prescrizione sia ricominciata. E' quindi necessario stabilire il momento iniziale della novella prescrizione, dopochè è cessata l'azione della causa instrutiva" (op. cit. n. ${ }^{\circ} 288$ ).

$6^{\circ}$ ) Esse conceito específico, a que alude Pugliese, não admite a menor dúvida. E já Troplong, como tantos outros, o tinha salientado, com estas palavras incisivas:

"Interrompre une prescription qui a dejà son cours c'est lui apporter un obstacle qui rende inutile le temps écoulé, et la force à recommencer comme si elle n'avait jamais eu de principe d'existence" (De La Prescription, 3. ${ }^{\mathrm{a}}$ ed. II, n. ${ }^{\circ}$ 536).

Gullloard, no seu clássico tratado, põe em realce, o mesmo conceito, mostrando que a interrupção destróe a prescriação que começara a correr e, de consequência, faz surgir uma nova prescrição, com estas palavras:

"L'interruption a pour effet d'anéantir dans le passé la prescription qui avait commencé à courir au profit du possesseur ou du debiteur; mais aussitôt que l'acte interruptif a produit son effet, si, come cela arrive le plus souvent, il n'a pas changé la situation juridique du possesseur ou du debiteur, celui-ci pourra recommencer une nouvelle prescription acquisitive ou liberatoire", etc. (L. Guilloard - De La Prescription, I, n. ${ }^{\circ}$ 264, 2. ${ }^{a}$ ed. 1901). 
No trecho citado, reporta-se Guilloard a outra passagem, em que já havia afirmado o desaparecimento da prescrição interrompida, como consequência da atitude do credor, pleiteando a integridade do seu direito, o concomitante aparecimento de uma nova prescrição.

7.') Laurent, nos seus "Principes de Droit Civil Français", não é menos incisivo, a interrupção faz desaparecer o passado, não exercendo influência alguma no futuro

"avec cet effet qui le temps qui a courru ne peut plus être compté pour servir à l'acomplissement de la prescription. L'interruption efface donc le passé: elle n'a pas d'influence sur l'avenir" (op. cit. vol. 32, n. $^{\circ} 77,3 .^{a}$ ed. 1878 ).

Mirabelli sustenta que a interrupção torna inutil o tempo passado, e tudo se passa como si, no momeno em que é feita, é que tivesse nascido a ação

rende inutile il tempo passato, come si in quel momento e non prima fosse nata l'azione (Della Prescrizione, $2 .^{a}$ ed. 1915, n. 68$)$.

$8^{\circ}$ ) Sôbre êsse característico, sôbre êsse efeito específico da interrupção são concordes todos os autores. Ela destróe o tempo passado. (Planiol e Ripert, III, 361).

Ela determina uma nova prescrição. Barassi, depois de mostrar que a interrupção produz um efeito diverso da suspensão, de salientar que não é um parêntesis aberto no curso da prescrição, assinala que tem ela

per effeto invece la cancelazione del periodo prescrizionale anteriormente decorso; cossichè, cessata la interruzione, ricomincia a decorrere per intero un periodo prescrizionale nuovo (Instituzioni di Diritto Privato p. 143 let. b ed. 1939).

De sorte que, a despeito das observações de D'Araentré, aliás justas, de que a matéria das interrupções é vasta e di- 
ficil: immensa et hujus lici materia et argumentum nigens (Troplong, op. cit. n. 539), quanto a êste ponto não há dissídio, não há discordância; a interrupção anula o passado e determina

o aparecimento de uma nova prescrição

autônoma, como si nenhuma outra tivesse existido. Todos os doutores chamados a capítulo não dissentiriam.

a única prescrição é a que aparece por fôrça do áto interruptivo.

9..$^{\circ}$ Ora, é evidente que a lei não podia disciplinar ou regular outra prescrição que não aquela que existia ao tempo em que entrou em vigor. Nem podia referir-se a um fantasma, que outra cousa não seria a prescrição apagada, cancelada, inutilisada, extinta. Nem podia atingir ou referir-se ao áto que a interrompeu, que êste tinha produzido todo seu efeito, na vigência da lei antiga, que não foi, neste ponto alterada.

$E$ aqui entramos, na segunda parte, nos princípios relativos ao direito intertemporal, não sem, mais uma vez, acentuar que a interrupção

fez surgir uma nova prescrição

e

apagou inteiramente o passado.

\section{II}

$\left.10 .^{\circ}\right)$ o Decreto 20.910 , de 6 de janeiro de 1932, si tivesse pura e simplesmente declarado que o prazo de cinco anos, para a prescrição a favor da Fazenda ficaria reduzido pela metade, teria alcançado as prescrições em curso. E' a lição de Dernburg: uma prescrição em curso não deve ser julgada segundo a lei vigorante no seu início, mas segundo a que entra em vigor durante o curso da prescrição: 
"Daher ist eine laufende Verjährung in der Regel nicht nach dem Gesetze zu beurteilen, welches bei ihrem Beginne galt, sondern nach dem Gesetze, das während des Laufes des Verjährung in Kraft trat". (Da Pandekten, $I, \S 36$, pg. 73, ed. 1911).

Isto si o prazo não foi de todo absorvido, ou si a própria lei não determinou o contrário, como aconteceu, por ocasião da entrada em vigor do Código Civil Italiano, que sotopoz a prescrição a um tratamento singular, no dizer de Ferrara, com o determinar que as prescrições iniciadas anteriormente ao Código continuassem reguladas pelas leis anteriores, mas, no caso de abreviação

le prescrizioni si compiranno col decorso del tempo fissato dal Codice, ma computabile dal giorno dell'attuazione di esso" (Trattato di Diritto Civile Italiano, I, pg. 277, ed. 1921).

$\left.11 .^{\circ}\right)$ Mas o decreto manteve o prazo de cinco anos, não o modificou. Apenas o reduzio no caso de ser interrompida a prescrição. Não vige, portanto, aquele princípio. Mas teria o decreto fôrça retroativa, para alcançar fátos consumados fóra de seu domínio? Não, porque não lhe atribuio essa fôrça, e a retroatividade não se desume. $E^{\prime}$ necessário que seja expressamente declarada. A verdadeira retroatividade não póde resultar senão de uma disposição formal do legislador. E' a lição de um dos mais recentes tratadistas da matéria:

La vraie rétroativité ne peut resulter que d'une disposition expresse, le juge, n'est en aucun cas autorisé à tirer, soit des travaux preparatoires, soit des circonstances qui on presidé à la confection de la loi, que celle-ci doive être appliqué rè- 
troativement. (Paul Roubier - Les Conflits des Lois dans le temps, n. 63).

Mesmo os que admitem a desnecessidade de ser expressa a vontade da lei, aceitando a retro ação tácita, exigem que se possa, com segurança, desumir

l'intenzione del legislatore di voler regolare anche i fatti sorti prima

pondo ainda de manifesto que, tratando-se de direito excecional

deve interpretarsi restritivamente, e quindi nel dubbio non deve ammetersi la retroattività (FERRARA, op. cit. pg. 271).

12. ${ }^{\circ}$ Não sendo retroativa, não podia alcançar fatos inteiramente consumados, ao tempo em que entrou em vigor. Só podia ter se referido à prescrição em curso e preceituado que esta só esta é que poderia ser interrompida uma vez, e que

uma vez interrompida, o novo prazo prescricional passaria a ser de dois anos e meio.

Porque, não se tendo atribuido o efeito retroativo, a sua função normal é só regular para o futuro - non ad facta preterita revocari. Mas no caso do decreto em aprêço, concorrem duas impossibilidades, de ordem material e jurídica

não póde atingir a prescrição anterior porque não existe, uma vez que desapareceu por fôrça do áto interruptivo

não póde referir-se a êste áto porque produzio êle o efeito e... exaurio-se,

e é cânone fundamental do nosso direito civil e com êste se afina o constitucional que a lei nova não póde exercer 
influência e abranger os fatos consumados sob o império da lei antiga. E tambem a lição da doutrina. E do mesmo modo que a lei nova

non può operare in modo che il fatto sia un non fatto, che i rapporti e diritti esistiti siano non esistiti (Fagella, in Bianchi, 2.0, pg. 158)

tambem não póde fazer surgir do limbo um fáto que a lei antiga aniquilou e extinguio, bem assim aquele que determinou êsse desaparecimento e fez nascer o fáto novo e com isto se exaurio.

Deante do exposto, passo a responder as perguntas formuladas na consulta, de modo global, pela seguinte fórma:

o decreto n. 20.910 só se refere às prescrições que encontrou em curso, que terấo a sua duração normal, no caso de cinco anos. A interrupção a que alude é a que fôr feita já sob o seu domínio, e só então é que, a partir dela, começará a correr o novo prazo, de dois anos e meio. 